\title{
Short communication: Characterizing metabolic and oxidant status of pastured dairy cows postpartum in an automatic milking system
}

\author{
M. F. Elischer, ${ }^{*}$ L. M. Sordillo, $†$ J. M. Siegford, ${ }^{*}$ and E. L. Karcher ${ }^{* 1}$ \\ *Department of Animal Science, and \\ †College of Veterinary Medicine, Michigan State University, East Lansing 48824
}

\begin{abstract}
The periparturient period represents a stressful time for dairy cows as they transition from late gestation to early lactation. Undesirable fluctuations in metabolites and impaired immune defense mechanisms near parturition can severely affect cow health and have residual effects on performance and longevity. Metabolic and oxidative stress profiles of multiparous and primiparous dairy cows in traditional parlor and feeding systems are well characterized, but status of these profiles in alternative management systems, such as grazing cows managed with an automatic milking system (AMS), are poorly characterized. Therefore, the objective of this case study was to characterize the metabolic and oxidant status of pastured cows milked with an AMS. It was hypothesized that primiparous and multiparous cows milked with an AMS would experience changes in oxidative and metabolic status after parturition; however, these changes would not impair cow health or production. Blood was collected from 14 multiparous and 8 primiparous Friesian-cross dairy cows at 1, 7,14 , and $21 \mathrm{~d}$ relative to calving for concentrations of insulin, glucose, nonesterified fatty acids (NEFA), $\beta$-hydroxybutyrate, reduced glutathione, oxidized glutathione, and antioxidant potential. Milk production and milking frequency data were collected postpartum. Milk production differed on d 7 and 14 between primiparous and multiparous cows and frequency was not affected by parity. Primiparous cows had higher levels of glucose than multiparous cows. No differences in insulin, NEFA, or $\beta$-hydroxybutyrate concentrations were noted between multiparous and primiparous cows postpartum, though days relative to calving significantly affected insulin and NEFA. Primiparous cows also had higher antioxidant potential than multiparous cows during the postpartum period. Results from this study
\end{abstract}

Received October 6, 2014

Accepted May 4, 2015

${ }^{1}$ Corresponding author: ekarcher@msu.edu show that, although responses were within expected ranges, periparturient multiparous cows responded differently than periparturient primiparous cows with respect to metabolic and oxidative measures during the postpartum period at this pastured-AMS dairy, suggesting different management strategies may need to be considered with primiparous and multiparous cows. Key words: automatic milking system, metabolic status, pasture, periparturient

\section{Short Communication}

The periparturient period, defined as 3 wk before and 3 wk following parturition, is a physiologically stressful time for dairy cattle. The physical, dietary, environmental, and social changes observed during this period are well characterized in traditional confinement operations that milk in parlors. Limited research has examined the effect of voluntary milking in an automatic milking system (AMS) on metabolic and immunological parameters of grazing periparturient dairy cows.

Primarily due to the stress of the periparturient period, a cow's immune system is impaired most in the week immediately before and the week immediately after parturition (Goff and Horst, 1997). The incidence of metritis, mastitis, retained fetal membranes, and mammary edema are all common issues postpartum, a time when a cow is known to naturally experience oxidative and metabolic stress (Sordillo and Aitken, 2009). Oxidative stress is a condition that occurs when excessive reactive oxygen species (ROS) are produced and antioxidant defenses are unable to neutralize the ROS. When a cow is expending a great deal more energy than is consumed, as is common in the early phase of lactation, a severe negative energy balance (NEB) can predispose her to different metabolic diseases (Mulligan and Doherty, 2008) and impair immune function (Goff and Horst, 1997).

Oxidative status is related to energy status in periparturient dairy cows (Bernabucci et al., 2005). Negative energy balance around calving plays a role in 
immunosuppression by acting on different leukocytes (neutrophils, lymphocytes) and proteins (e.g., immunoglobulins, complement) crucial for defense against infection and illness (Kehrli et al., 1989, 1990; Scalia et al., 2006). The immune system will not function efficiently when there are deficiencies in nutrition (e.g., energy, protein), as occurs with NEB during the periparturient period (Goff and Horst, 1997). Strong evidence exists that metabolic changes associated with calving and lactogenesis affect immune function regardless of milking or feeding strategy (Goff, 2006).

The objective of our case study was to characterize the metabolic and oxidative status of multiparous and primiparous pastured periparturient cows milked with an AMS. We hypothesized that grazing primiparous and multiparous cows milked with an AMS would experience changes in oxidative and metabolic status after parturition. Changes in any parameters of interest would not impair cow health or production; however, a difference between the primiparous and multiparous cattle would occur, with primiparous cows exhibiting greater changes. The combination of a pasture-based diet and the flexibility of an AMS would be less demanding on the cows during the periparturient period.

All procedures were approved by the Michigan State University Institutional Animal Care and Use Committee before the start of the experiment. Fourteen multiparous (MC) and 8 primiparous (PC) Friesian-cross dairy cows were enrolled based on expecting calving date. The study was conducted from April 12 to July 26, 2012, at a commercial dairy farm in central Michigan with 111 cows in the milking herd at the time of the study. The diet of the cows was pasture-based, containing a mixture of red clover (Trifolium pratense), white clover (Trifolium repens), and orchard grass (Dactylis glomerata). The temperature during the experimental period ranged from 8.3 to $34.4^{\circ} \mathrm{C}$, with a mean of 22.7 $\pm 1.2^{\circ} \mathrm{C}$. A total of $84.6 \mathrm{~mm}$ of precipitation was reported during the study period. Multiparous cows were enrolled $21 \mathrm{~d}$ before expected parturition date and PC within $1 \mathrm{~d}$ after parturition. Primiparous cows were not enrolled before calving due to the breeding program at the farm. Natural service was used for all PC, thus an accurate record of breeding was not available to predict a calving date with the same accuracy of MC bred with AI. All cows were monitored for health disorders during the experimental period and no animals were diagnosed with a health incident.

Dry cows and heifers were housed on pasture as one group and were rotated between pastures as necessary to meet the grazing needs of the cows throughout the spring and summer. Water was available ad libitum. Indoor access was limited, but a pack-bedded barn was available for calving if necessary. Cows were allowed to calve on pasture without human interference.

The milking herd was managed as a single group under the same breeding, feeding, grazing, and AMS milking protocols. The cows were housed in a loose housing system with $24 \mathrm{~h} / \mathrm{d}$ access to outdoor pasture. The lactating herd was grazed rotationally on 101.2 ha of pasture subdivided into 26 paddocks. Water was available indoors only, ad libitum, from 2 automatic water troughs at opposite ends of the barn. Two Lely A3 Astronaut AMS (Lely, Maassluis, the Netherlands) were available for milking $24 \mathrm{~h} / \mathrm{d}$ except for a total of $40 \mathrm{~min} / \mathrm{AMS}$ per day when the units closed for cleaning and any repairs or servicing that was necessary. All cows had equal access to both AMS units; no management, traffic, or barn design restrictions were placed on the animals for AMS use. All cows wore a transponder around their neck for individual identification by the AMS and routing to pasture via a sort gate.

Sampling days for MC were $-21,-14,-7,1,7,14$, and $21 \mathrm{~d}$ relative to calving (DRTC). Primiparous cows were only sampled $1,7,14$, and $21 \mathrm{~d}$ after calving. Blood was collected from the coccygeal tail vein via venipuncture with Vacutainer needles and collection tubes (Becton Dickinson, Franklin Lakes, NJ). Twentygauge single-use needles were used to collect blood in $\operatorname{EDTA}(\mathrm{K} 2)$ tubes (for analysis of insulin, glucose, NEFA, and BHBA) and heparin tubes [for the analysis of antioxidant potential (AOP), reduced glutathione (GSH), and oxidized glutathione (GSSG)]. All blood samples were collected, stored, and processed according to manufacturer instructions for each individual assay. Careful consideration was given to the type of tube used to collect blood, preparation of blood or plasma for storage, temperature of storage, and duration of storage before performing the assay to ensure accuracy of results.

Insulin and glucose plasma samples were sent for analysis to the Diagnostic Center for Population and Animal Health at Michigan State University. Insulin was assessed via a radioimmunoassay (Human Insulin RIA Kit; Millipore Corporation, Billerica, MA). Glucose was quantified by the hexokinase G-6-PDH method using an Olympus AU640e analyzer (Olympus, Center Valley, PA). The reagent necessary for the assay was obtained from Beckman Coulter Inc. (Brea, CA). Assays for NEFA and BHBA concentrations were performed on plasma samples using commercial enzymatic colorimetric kits (NEFA: NEFA HR kit, Wako Chemicals USA, Richmond, VA; BHBA: procedure no. 2440, Stanbio Laboratory, Boerne, TX).

The GSH-to-GSSG ratio of each cow on all sampling days was evaluated using Bioxytech GSH/GSSG-412 
Kit (Oxis Research, Burlingame, CA). Whole blood was aliquoted from the heparin collection tubes and a thiol scavenger (M2VP) was added to the samples analyzed for GSSG; untreated whole-blood samples were analyzed for GSH. The ratio of GSH to GSSG was determined by the presence of 5,5'-dithiobis(2nitrobenzoic acid) and NADPH.

Total antioxidant potential in plasma samples was evaluated with a commercial kit (Bioxytech AOP-450; Oxis Research, Foster City, CA), to determine the copper-reducing power of antioxidants present. Only postpartum data were available for both $\mathrm{PC}$ and $\mathrm{MC}$, thus only the statistical results from postpartum data are reported. All statistics were performed using SAS 9.2 (SAS Institute Inc., Cary, NC) with significance declared at $P<0.05$. A mixed model (PROC MIXED) was used to analyze all metabolic and oxidative stress parameters, as well as milk production and milking frequency data. The model was as follows:

$$
\mathrm{Y}_{\mathrm{ijk}}=\mu+\text { DRTC }_{\mathrm{j}}+\mathrm{P}_{\mathrm{k}}+(\mathrm{DRTC})(\mathrm{P})_{\mathrm{jk}}+\mathrm{e}_{\mathrm{ijk}},
$$

where $Y_{\mathrm{ijk}}$ is the dependent variable for the metabolic or oxidative stress or milking parameter of interest from $\mathrm{cow}_{\mathrm{i}}$ on the day relative to calving (DRTC: 1, 7,14 , or $21 \mathrm{~d}$ ) of parity $_{\mathrm{k}}(\mathrm{P}: \mathrm{MC}$ or $\mathrm{PC}$ ) and e as the residuals from the ith cow on the jth day relative to calving with the kth parity. Day relative to calving was a repeated measure. For each response variable, the covariate structure for parity was chosen based on lowest $\mathrm{BIC}$ and $\mathrm{AIC}$ values. Least squares means \pm standard error of the mean are presented. Data were adjusted using the Tukey-Kramer method in SAS for multiple pair-wise comparisons.

Milk production was affected by the interaction of DRTC and parity $(P<0.01$; Figure $1 \mathrm{~A})$. Milk yield increased from d $1(7.5 \pm 1.3 \mathrm{~kg})$ to $7(20.5 \pm 0.9 \mathrm{~kg}$; $P<0.05$ ) for MC and consistent production of about $22 \mathrm{~kg} / \mathrm{d}$ for 14 and 21 d postpartum. Primiparous cows' yield increased less dramatically between $\mathrm{d} 1$ and 7 $(7.0 \pm 1.8$ vs. $12.3 \pm 1.3 \mathrm{~kg} ; P<0.01)$ and continued to increase through d $21(P<0.05)$. Multiparous cows produced significantly more milk $(P<0.05)$ on $\mathrm{d} 7$ and 14 compared with PC, but yields on d 21 did not differ significantly. Milking frequency was also affected by DRTC $(P<0.05)$, but parity or the interaction of parity and DRTC did not play a significant role (Figure 1B). An increase in milkings per day was observed on d 21 compared with d $1(1.7 \pm 0.1$ vs. $2.6 \pm 0.2 ; P<$ 0.05 ), but frequency on $\mathrm{d} 7$ and 14 were not different from each other or d 1 and 21. Milk yield values and milking frequency for PC on d 14 in our study were similar to those reported by Donohue et al., (2010) for
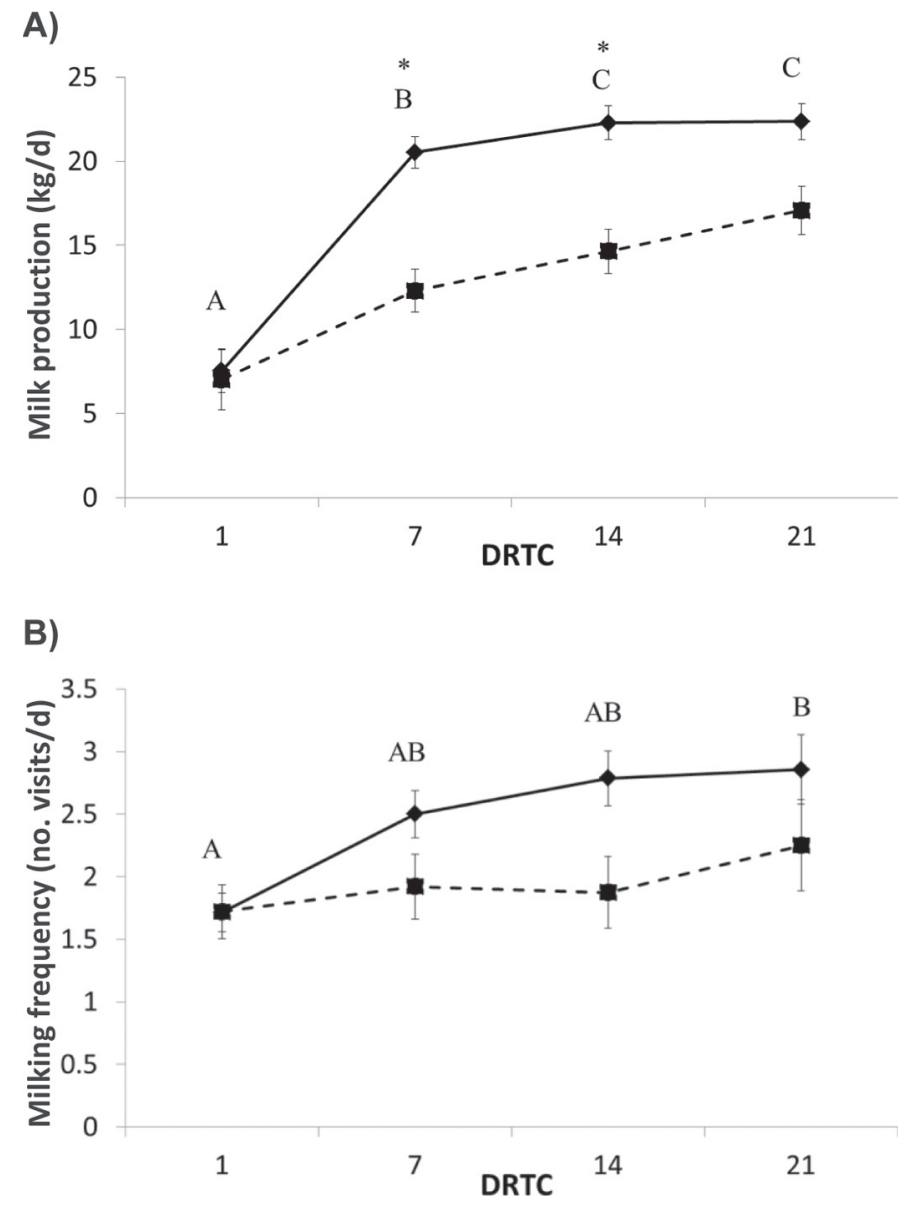

Figure 1. Milk production (A) and milking frequency (B) for 14 multiparous $(\bullet)$ and 8 primiparous ( $\mathbf{\square})$ pastured periparturient dairy cows milked in an automatic milking system. (A) Milk production [day relative to calving (DRTC), $P<0.0001$; parity, $P<0.01$; interaction of DRTC and parity, $P<0.01$ ]. (B) Milking frequency (DRTC, $P<$ $0.05)$. Asterisks $(*)$ indicate significant difference between primiparous and multiparous cows on a given day and letters $(\mathrm{A}-\mathrm{C})$ indicate significant difference between days across primiparous and multiparous cows $(P<0.05)$.

pastured first-lactation cattle (14-d cumulative milk yield of $162.39 \mathrm{~kg}$ and average milking frequency of $1.74 \times / \mathrm{d}$ in spring 2007; $233.69 \mathrm{~kg}$ and 2.31 milkings/d in autumn 2008); milk yield data of multiparous herdmates and was not reported.

The flexibility of an AMS allows for cows to be milked more frequently and could thus lead to increased metabolic stress; however, varying results have been reported on this topic. Our study evaluated blood concentrations of glucose, insulin, NEFA, and BHBA across the experimental period. Glucose concentrations were significantly higher in $\mathrm{PC}$ than $\mathrm{MC}$ during the postpartum period on all days except d $1(P<0.05)$. Both PC and MC maintained high glucose concentrations postpartum, with the highest value for $\mathrm{MC}$ on $\mathrm{d}$ 
A)

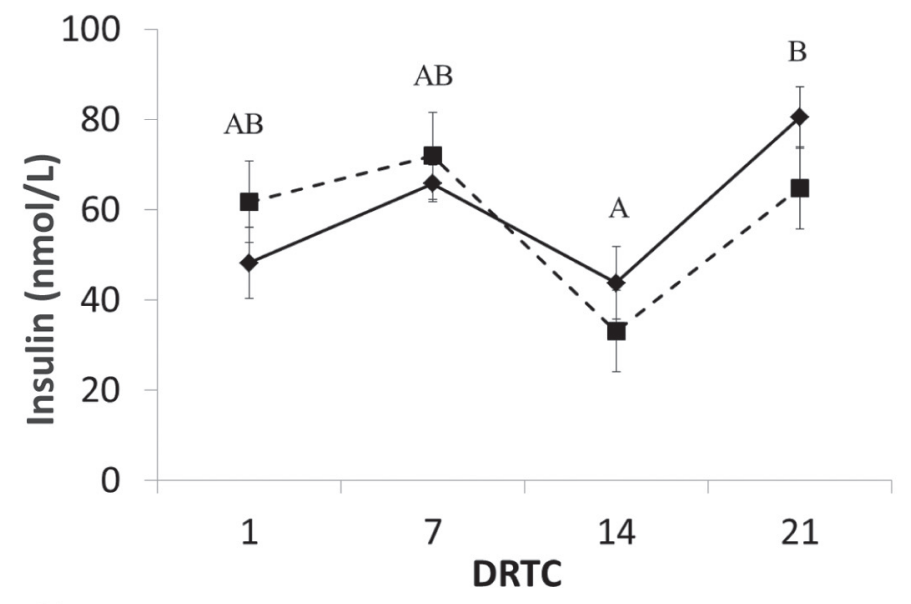

C)

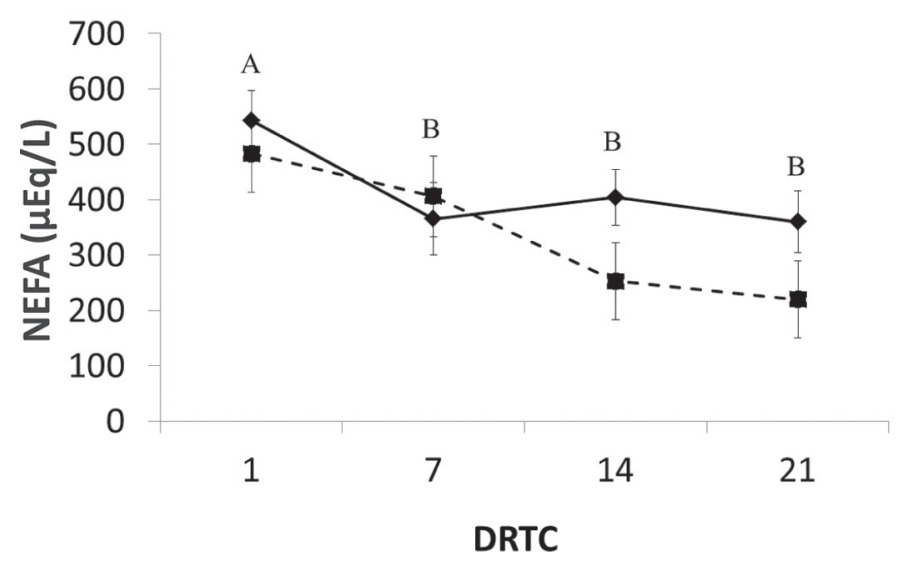

B)

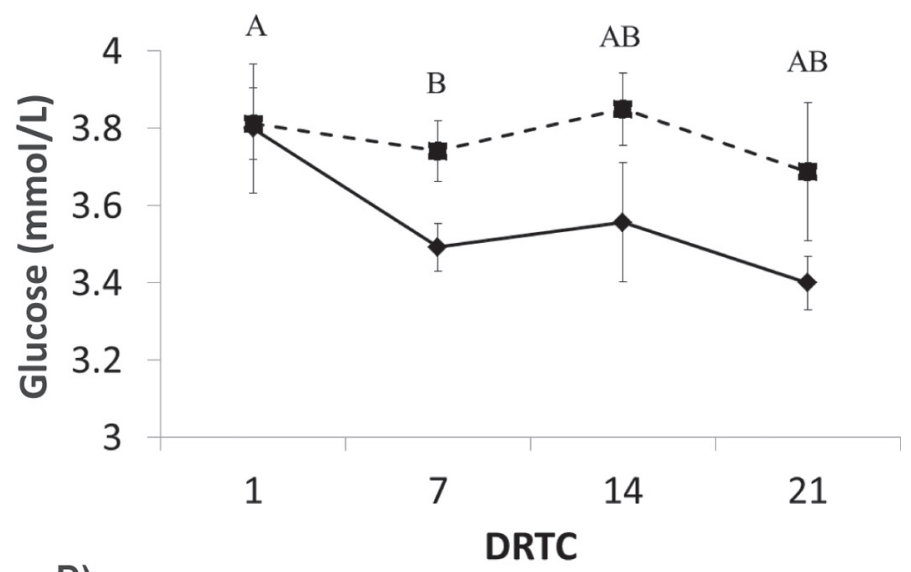

D)

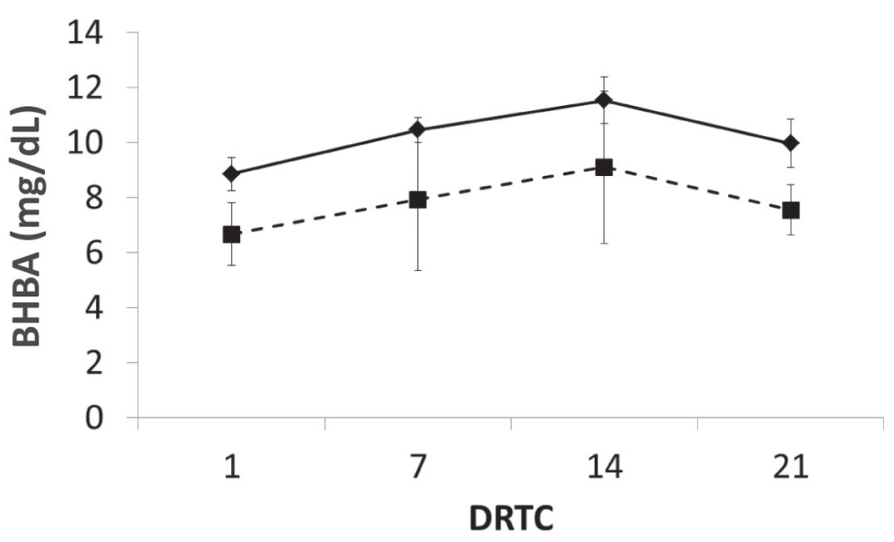

Figure 2. Metabolic parameters for 14 multiparous ( ) and 8 primiparous ( $)$ pastured periparturient dairy cows milked in an automatic milking system. (A) Insulin [day relative to calving (DRTC), $P<0.01$ ]; (B) glucose (DRTC, $P<0.01$; parity, $P<0.05$; interaction of DRTC and parity, $P<0.05$ ); (C) NEFA (DRTC, $P<0.01$ ); (D) BHBA. Letters $(A, B)$ indicate significant difference between days across primiparous and multiparous cows $(P<0.05)$.

$1(3.8 \pm 0.1 \mathrm{mmol} / \mathrm{L})$ and declining thereafter, whereas PC peaked at d $14(3.9 \pm 0.1 \mathrm{mmol} / \mathrm{L})$, with other days not differing significantly from this value. An effect of DRTC was noted on plasma concentrations of glucose $(P=0.0011)$ and insulin $(P=0.0003 ;$ Figure $2 \mathrm{~A}$ and $\mathrm{B})$. Insulin concentrations declined at $\mathrm{d} 14$ for both $\mathrm{PC}(33.1 \pm 9.0 \mathrm{nmol} / \mathrm{L})$ and $\mathrm{MC}(43.7 \pm 6.8 \mathrm{nmol} / \mathrm{L})$ compared with d 7 (MC: $65.9 \pm 6.8 \mathrm{nmol} / \mathrm{L}$; PC: 72.0 $\pm 9.7 \mathrm{nmol} / \mathrm{L}$ ), but increased on d 21 (Figure 2A).

Profiles for NEFA and BHBA concentrations were also examined. Average NEFA concentrations were significantly higher on d $1(512.9 \pm 44.6 \mu \mathrm{Eq} / \mathrm{L})$ compared with NEFA concentrations on all other days (d 7 $=385.5 \pm 45.2 \mu \mathrm{Eq} / \mathrm{L} ; \mathrm{d} 14=328.6 \pm 44.1 \mu \mathrm{Eq} / \mathrm{L} ; \mathrm{d}$ $21=290.0 \pm 43.6 \mu \mathrm{Eq} / \mathrm{L} ; P<0.05)$. However, parity did not affect NEFA concentrations (Figure 2C). Parity or DRTC did not have an effect on plasma concentra- tions of BHBA (Figure 2D). Limited differences were observed in NEFA and BHBA concentrations between primiparous Friesian cows milked in an AMS and a parlor; however, all cows in the study received a TMR (Abeni et al., 2005).

Daily milk yield is lower in cattle receiving a primarily pasture-based diet compared with those housed indoors and fed a TMR (Kolver and Muller, 1998; White et al., 2002). Multiparous cows in our study experienced increased blood glucose concentrations and slightly elevated NEFA concentrations at calving. The increase in NEFA at calving and then the rapid decline by $\mathrm{d}$ 7 did not result in increased BHBA concentrations, as typically seen in periparturient dairy cows. These results are not consistent with published studies reporting an increase in NEFA at parturition coupled with increased BHBA concentrations 2 to 3 wk after calving 
(Cavestany et al., 2005; Goff, 2006). However, cows in our study were not experiencing a severe NEB at the onset of lactation, as evidenced by their blood glucose and NEFA concentrations. The primary pasture diet, variable milk intervals, and lower milk yield may have resulted in less metabolic stress compared with cows in a conventional system.

Glucose is vital for proper metabolic and immune function; it is the main metabolic fuel for many cells (LeBlanc, 2010). Low levels of glucose have been linked to a less effective pathogen-killing oxidative burst from polymorphonuclear neutrophils and are often seen at the same time as decreases in GSH concentrations (Ingvartsen et al., 2003), both of which impair host defenses. The cows in our study maintained high levels of glucose and GSH and were not diagnosed with metabolic disorders during the experimental period. Reduced glutathione was affected by DRTC $(P<0.01)$, but not parity (Figure 3A). The average concentration of GSH declined after parturition with a lower concentration on d 7 compared with d 1 (226.2 \pm 13.1 vs. $287.8 \pm 13.6$ $\mu M ; P<0.01)$. The GSH concentrations in our study were lower at $\mathrm{d} 1$ and 21 compared with data published for Holstein cows fed a TMR using the same GSH/ GSSG-412 kit (Sordillo et al., 2007).

An interaction of parity and DRTC for GSSG $(P$ $<0.05)$ was observed. Multiparous cows and PC had similar d-1 concentrations $(4.0 \pm 0.7$ vs. $4.1 \pm 1.2 \mu M$, respectively). Primiparous cows' values declined on $\mathrm{d}$ 7 and 21, but were elevated on d 14 (Figure 3B). The ratio of GSH to GSSG was significantly affected by DRTC $(P<0.05)$, but parity and the interaction of DRTC and parity were not significant (Figure 3C). The ratio declined from $\mathrm{d} 1(199.0 \pm 40.2)$ to $7(133.5$ \pm 23.1 ), then increased and remained stable on $\mathrm{d} 14$ $(238.7 \pm 125.1)$ and $21(236.3 \pm 36.9)$. In a study of twin cows with 1 twin milked in a parlor twice per day and the other in AMS $(2.69 \pm 0.6$ milking/d), the AMS
A)

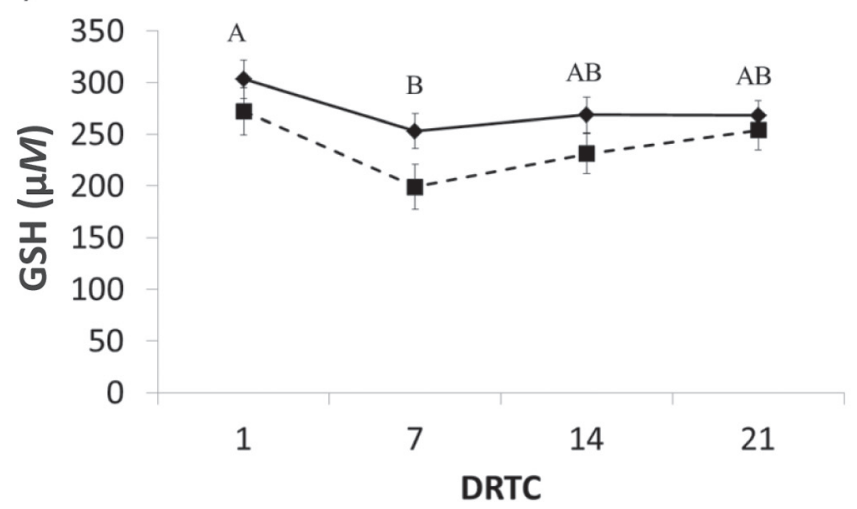

C)

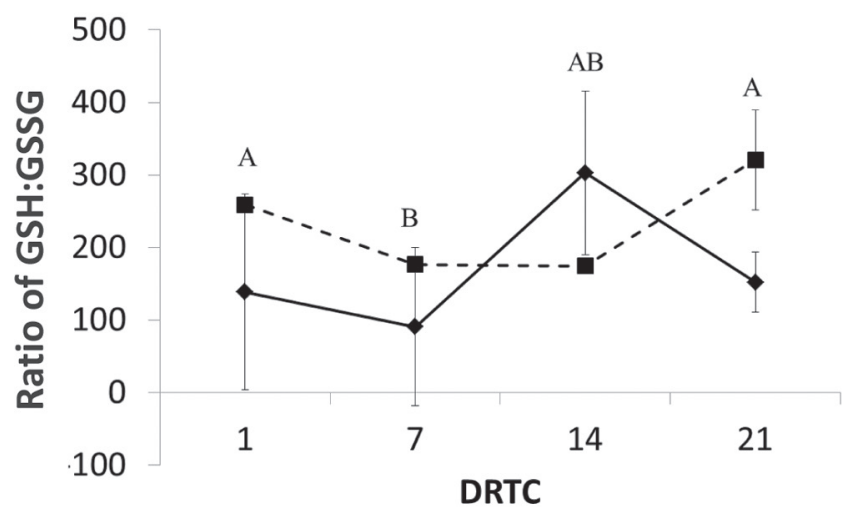

B)

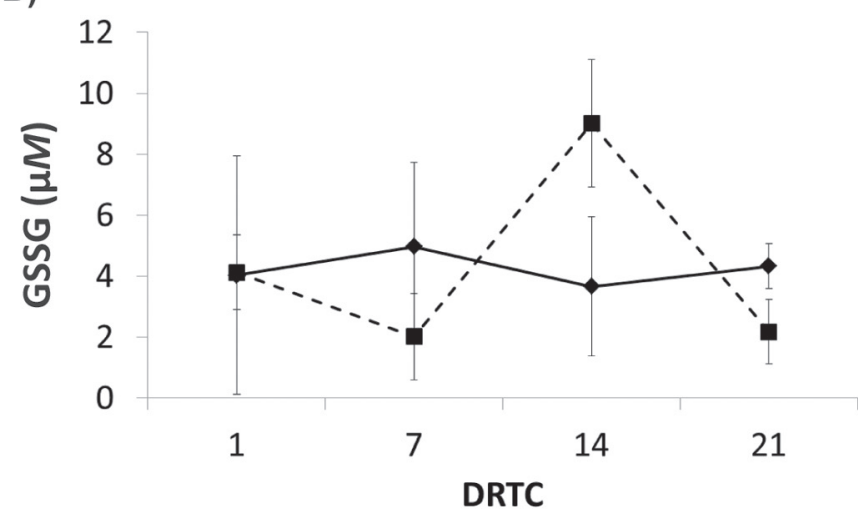

D)

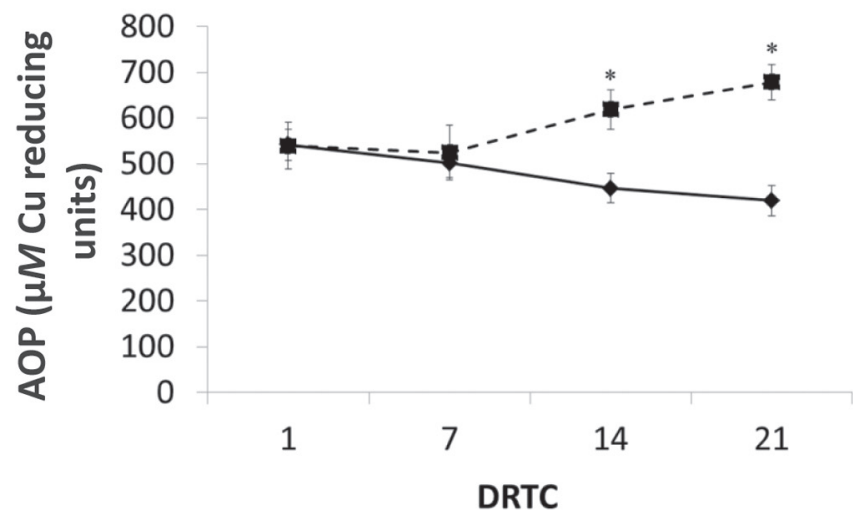

Figure 3. Oxidative parameters for 14 multiparous $(\bullet)$ and 8 primiparous $(\mathbf{\square})$ pastured periparturient dairy cows milked in an automatic milking system. (A) Reduced glutathione [GSH; day relative to calving (DRTC), $P<0.01$ ]; (B) oxidized glutathione (GSSG; interaction of DRTC and parity, $P<0.05$ ); (C) GSH:GSSG (DRTC, $P<0.05$ ); and D) antioxidant potential (AOP; parity, $P<0.05$; interaction of DRTC and parity, $P<0.01)$. Asterisks $(*)$ indicate significant difference between primiparous and multiparous cows on a given day and letters $($ A,B) indicate significant difference between days across primiparous and multiparous cows $(P<0.05)$. 
twin exhibited lower reactive oxygen metabolites in the blood compared with the parlor milked cow in early lactation (Abeni et al., 2008). The values obtained for GSH, GSSG, and the ratio of GSH to GSSG in the present study are similar to those previously reported for multiparous Holstein cows fed a TMR and housed in a freestall barn (Sordillo et al., 2007).

Oxidative stress is associated with many different disease states; however, it has not yet been established whether excessive ROS is the result or cause of impaired health (Sordillo and Aitken, 2009). Quantifying the antioxidant potential is a means of estimating overall redox status, with higher values indicating more protection from oxidant stress (O'Boyle et al., 2006). Cows in the current study maintained high AOP concentrations compared with previously published data of cattle fed a TMR and milked in a parlor after parturition through $21 \mathrm{~d}$, with $\mathrm{PC}$ values higher than $\mathrm{MC}$ on all days except immediately postpartum (Figure 3D). The antioxidant defenses of PC increased over time, contrasting with published data reporting either a decline in antioxidants postpartum (Sordillo et al., 2007) or an increase in ROS (Bernabucci et al., 2005). Plasma AOP was significantly affected by the interaction of DRTC and parity $(P<0.01)$. A lower concentration of GSH in PC compared with MC is interesting because $\mathrm{PC}$ maintained similar or higher AOP concentrations than MC postpartum. This may suggest PC are overall more protected from cellular oxidization; however, specific pathways could still be compromised.

Ours is the first study to characterize the metabolic status and oxidant status of periparturient dairy cows milking with an AMS and managed in a pasture-based system. This unique method of dairy management did not appear to negatively affect the parameters examined in our study. As expected, postpartum changes in metabolic and immune parameters did occur in the general patterns that have been reported in other dairy management systems, confirming the connection of these systems and many changes that occur with the onset of lactation. It must be mentioned that the changes observed in our study were not associated with any illness or injury in the cows and that some parameters were below thresholds associated with increased disease risk. Greater differences in milk yield and metabolic parameters were seen compared with reported values for traditional milking and feeding systems; however, oxidative stress parameters were more similar. Maintaining optimal metabolic health and immune function is crucial for an overall healthy cow, especially after parturition. Metabolic and oxidative status change after calving, and this change is experienced differently by $\mathrm{MC}$ and $\mathrm{PC}$, suggesting that management strategies for $\mathrm{PC}$ and $\mathrm{MC}$ postpartum may need to be considered to optimize the health, welfare, and production of pastured cows milking with an AMS.

\section{ACKNOWLEDGMENTS}

Support for this study was received from a grant to Michigan State University from the W.K. Kellogg Foundation (Battle Creek, MI) and an Animals in Agriculture Initiative grant (Michigan State University). The authors wish to acknowledge the technical assistance of the Sordillo Laboratory, Allen Laboratory, and RTSF Genomics Core (Michigan State University). Statistical assistance was provided by the College of Agriculture and Natural Resources Statistical Consulting Center and Jim Liesman (Michigan State University).

\section{REFERENCES}

Abeni, F., L. Calamari, F. Calza, M. Speroni, G. Mertoni, and G. Pirlo. 2005. Welfare assessment based on metabolic and endocrine aspects in primiparous cows milked in a parlor or with an automatic milking system. J. Dairy Sci. 88:3542-3552. http://dx.doi. org/10.3168/jds.S0022-0302(05)73039-3.

Abeni, F., M. G. Terzano, M. Speroni, L. Migliorati, M. Capelletti, F. Calza, L. Bianchi, and G. Pirlo. 2008. Evaluation of milk enzymes and electrolytes, plasma metabolites, and oxidative status in twin cows milked in an automatic milking system or twice daily in a conventional milking parlor. J. Dairy Sci. 91:3372-3384. http:// dx.doi.org/10.3168/jds.2008-1039.

Bernabucci, U., B. Ronchi, N. Lacetera, and A. Nardone. 2005. Influence of body condition score on the relationship between metabolic status and oxidative stress in periparturient dairy cows. J. Dairy Sci. 88:2017-2026. http://dx.doi.org/10.3168/jds.S0022$0302(05) 72878-2$.

Cavestany, D., J.E. Blanc, M. Kulcsar, G. Uriarte, P. Chilibroste, A Meikle, H. Febel, A. Ferraris, and E. Krall. 2005. Studies of transition cow under a pasture-based milk production system: Metabolic profiles. J. Vet. Med. A. 52:1-7. http://dx.doi.org/10.1111/ j.1439-0442.2004.00679.x.

Donohue, R. H., K. L. Kerrisk, S. C. Garcia, D. A. Dickeson, and P. C. Thomson. 2010. Evaluation of two training programs aimed to improve early lactation performance of heifers in a pasture-based automated milking system. Anim. Prod. Sci. 50:939-945. http:// dx.doi.org/10.1071/AN10061.

Goff, J. P. 2006. Major advances in our understanding of nutritional influences on bovine health. J. Dairy Sci. 89:1292-1301. http:// dx.doi.org/10.3168/jds.S0022-0302(06)72197-X.

Goff, J. P., and R. L. Horst. 1997. Physiological changes at parturition and their relationship to metabolic disorders. J. Dairy Sci. 80:12601268. http://dx.doi.org/10.3168/jds.S0022-0302(97)76055-7.

Ingvartsen, K. L., R. J. Dewhurst, and N. C. Friggens. 2003. On the relationship between lactational performance and health: is it yield or metabolic imbalance that cause production diseases in dairy cattle? A position paper. Livest. Prod. Sci. 83:277-308. http:// dx.doi.org/10.1016/S0301-6226(03)00110-6.

Kehrli, M. E., Jr., J. R. Jesse, P. Goff, J. A. Harp, and J. R. Thurston. 1990. Effect of preventing periparturient hypocalcemia in cows by parathyroid hormone administration on hematology, congluitinin, immunoglobulin, and shedding of Staphylococcus aureus in milk. J. Dairy Sci. 73:2103-2111. http://dx.doi.org/10.3168/jds.S00220302(90)78890-X.

Kehrli, M. E., B. J. Nonnecke, and J. A. Roth. 1989. Alterations in bovine neutrophil function during the periparturient period. Am. J. Vet. Res. 50:207-214.

Kolver, E. S., and L. D. Muller. 1998. Performance and nutrient intake of high producing Holstein cows consuming pasture or a 
total mixed ration. J. Dairy Sci. 81:1403-1411. http://dx.doi. org/10.3168/jds.S0022-0302(98)75704-2.

LeBlanc, S. 2010. Monitoring metabolic health of dairy cattle in the transition period. J. Reprod. Dev. 56:S29-S35. http://dx.doi. org $/ 10.1262 /$ jrd.1056S29

Mulligan, F. J., and M. L. Doherty. 2008. Production diseases of the transition cow. Vet. J. 176:3-9. http://dx.doi.org/10.1016/j. tvjl.2007.12.018.

O'Boyle, N., C. M. Corl, J. C. Gandy, and L. M. Sordilo. 2006. Relationship of body condition score and oxidant stress to tumor necrosis factor expression in dairy cattle. Vet. Immunol. Immunopathol. 113:297-304. http://dx.doi.org/10.1016/j.vetimm.2006.05.013.

Scalia, D., N. Lacetera, U. Bernabucci, K. Demeyere, L. Duchateau, and C. Burvenich. 2006. In vitro effect of nonesterified fatty acids on bovine neutrophils oxidative burst and viability. J. Dairy Sci. 89:147-154. http://dx.doi.org/10.3168/jds.S0022-0302(06)720781.
Sordillo, L. M., and S. L. Aitken. 2009. Impact of oxidative stress on the health and immune function of dairy cattle. Vet. Immunol. Immunopathol. 128:104-109. http://dx.doi.org/10.1016/j. vetimm.2008.10.305

Sordillo, L. M., N. O'Boyle, J. C. Gandy, C. M. Corl, and E. Hamilton. 2007. Shifts in thiroedoxin reductase activity and oxidant status in mononuclear cells obtained from transition dairy cows. J. Dairy Sci. 90:1186-1192. http://dx.doi.org/10.3168/jds.S00220302(07)71605-3.

White, S. L., G. A. Benson, S. P. Washburn, and J. T. Green Jr.. 2002. Milk production and economic measures in confinement or pasture systems using seasonally calved Holstein and Jersey cows. J. Dairy Sci. 85:95-104. http://dx.doi.org/10.3168/jds.S00220302(02)74057-5. 